\title{
A NEW ADVISOR SYSTEM TO DETECT THE 'TAP HOLE WHISTLING AND SPLASHING' IN A BLAST FURNACE
}

\author{
NOWY SYSTEM DORADCZY DO DETEKCJI ZJAWISKA 'WYDMUCHIWANIA I ROZPRYSKU' \\ Z OTWORU SPUSTOWEGO W WIELKIM PIECU
}

\begin{abstract}
The objective is to determine the moment from which a Blast Furnace tap hole must be closed and consequently the exit of materials (hot metal and slag), by studying the conventional video images obtained at the exit of the tap hole of the BF in order to optimize the process performance. This point is characterized by a remarkable increase in the width of the flow which corresponds to the maximum exit of the slag surrounding the melted metal (and a significant decrease in the pig iron). This video based system is compared to the information provided by the EMF signals (electromotive forces).

Keywords: blast furnace, optimization
\end{abstract}

\section{Images processing}

The first step is the extraction of the MPEG video images (Moving Picture Experts Group) to a JPG format (Joint Photographic Experts Group) (Fig. 1 left). The digitalized images present a very noisy signal due to the amount of smoke and steam existing in the environment where they were taken. In order to avoid this noise interference in the measurements that are to be taken, a filtering is carried out via an average of the images for a variable period of time (Fig. 1 right). It has been observed that the optimum values are around 10 seconds (50-250 frames).

The averaged colour image (RGB) obtained is divided into the various channels in HSL space (Hue, Saturation, Lightness). Of the three grey levels images, the images that correspond to the HUE channel are studied exclusively (Fig. 2)

A histogram is obtained for the HUE image. This histogram presents various low values peaks for HUE intensity (the complete images present a maximum HUE intensity with values near 255 , but do not correspond to the specified work area or equivalent to the tonal range)

* CENTRO NACIONAL DE INVESTIGACIONES METALÚRGICAS (CSIC-CENIM) - AVE. GREGORIO DEL AMO, 828040 MADRID, SPAIN.

** E T S I O, UNIVERSIDAD DE OVIEDO - C/ INDEPENDENCIA, 1333004 OVIEDO, SPAIN.

**** DPTO. INGENIERÍA METALÚRGICA, UNIV. DE CONCEPCIÓN EDMUNDO LARENAS, 285 CONCEPCIÓN, CHILE. 


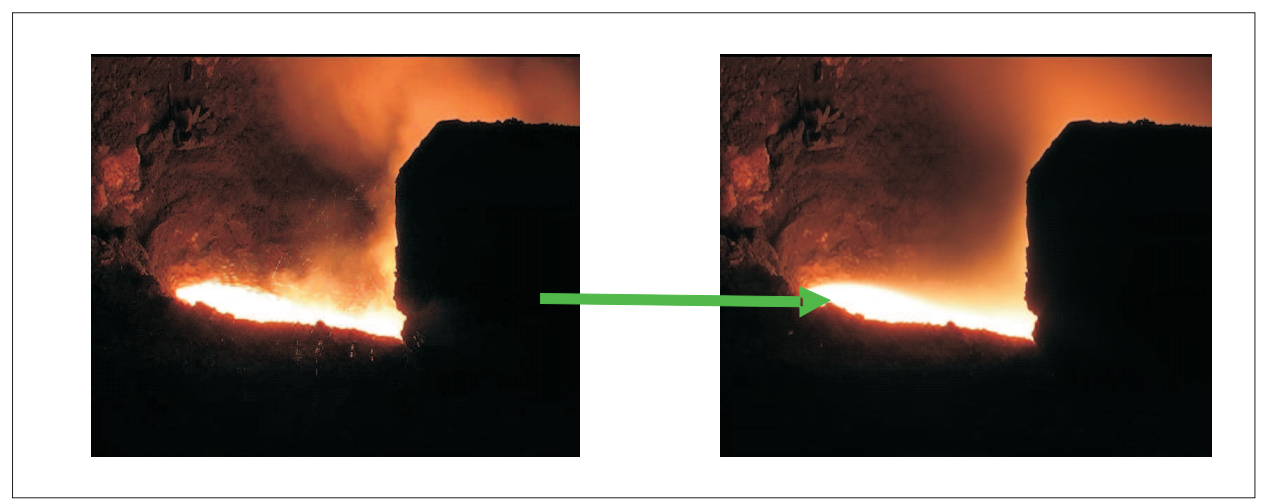

Fig. 1. Images obtained from the tap hole

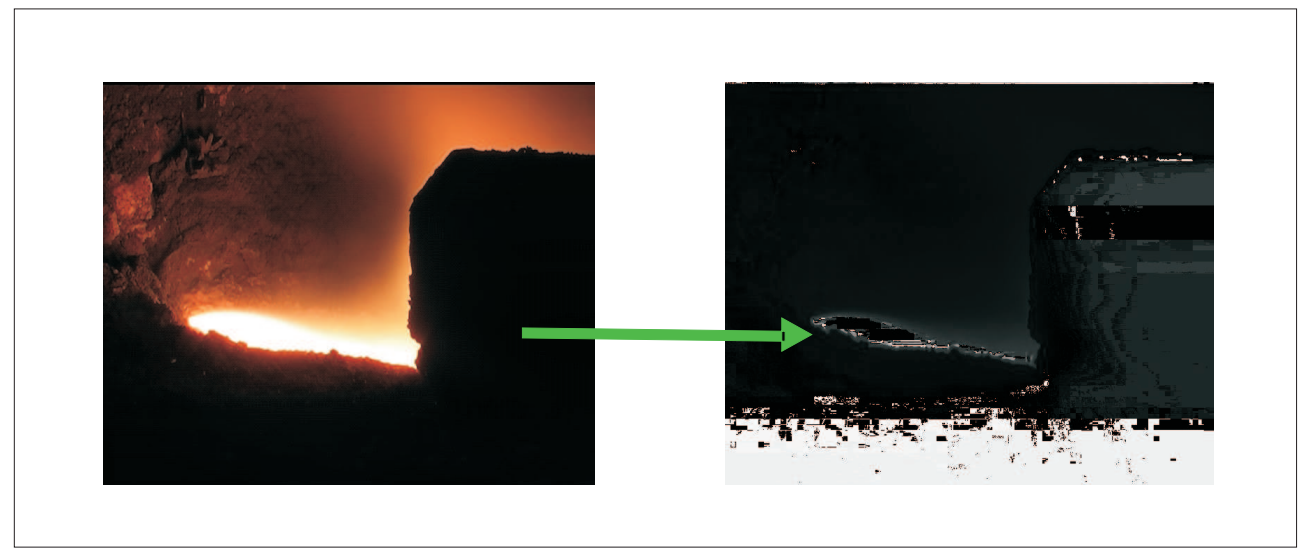

Fig. 2. The image is thresholded

Of the binary images $\mathrm{Bin}(\mathrm{H} 1)$ and $\mathrm{Bin}(\mathrm{H} 2)$, the corresponding $\mathrm{Ce}$, and smelted metal, $\mathrm{Cm}$ slag boundaries are searched for using a mask. The $\mathrm{Cm}$ boundaries are much clearer and are sufficiently determined with the absence of noise, what does not occur with $\mathrm{Ce}$.

The $\mathrm{Ce}$ and $\mathrm{Cm}$ boundaries are melted into a single binary image. Positions for $\mathrm{Cm},\left(\mathrm{x}_{m i}, \mathrm{y}_{m i}\right)$, are determined first. (Fig. 3). The positions $\left(\mathrm{x}_{e i}, \mathrm{y}_{e i}\right)$ are calculated as a first perpendicular cut to the Ce line from $\left(\mathrm{x}_{m i}, \mathrm{y}_{m i}\right)$. Only the superior curve positions (1) are calculated, what isn't done for the lower parts since they do not appear in many videos. During the tapping (2), a graph is drawn with these calculated data (Fig. 4) and a warning to plant operator would appear, indicating the different tapping phases (3) and when the tapping must be finished.
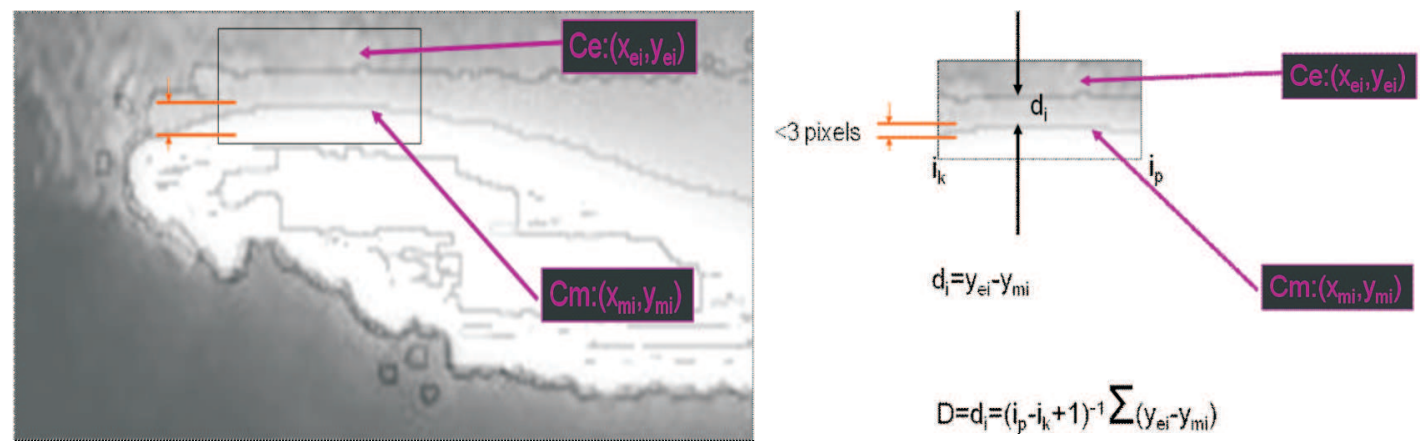

$$
D=d_{i}=\left(i_{p}-i_{k}+1\right)^{-1} \sum\left(y_{e-i}-y_{m i}\right)
$$

Fig. 3. Digital Images treatment 


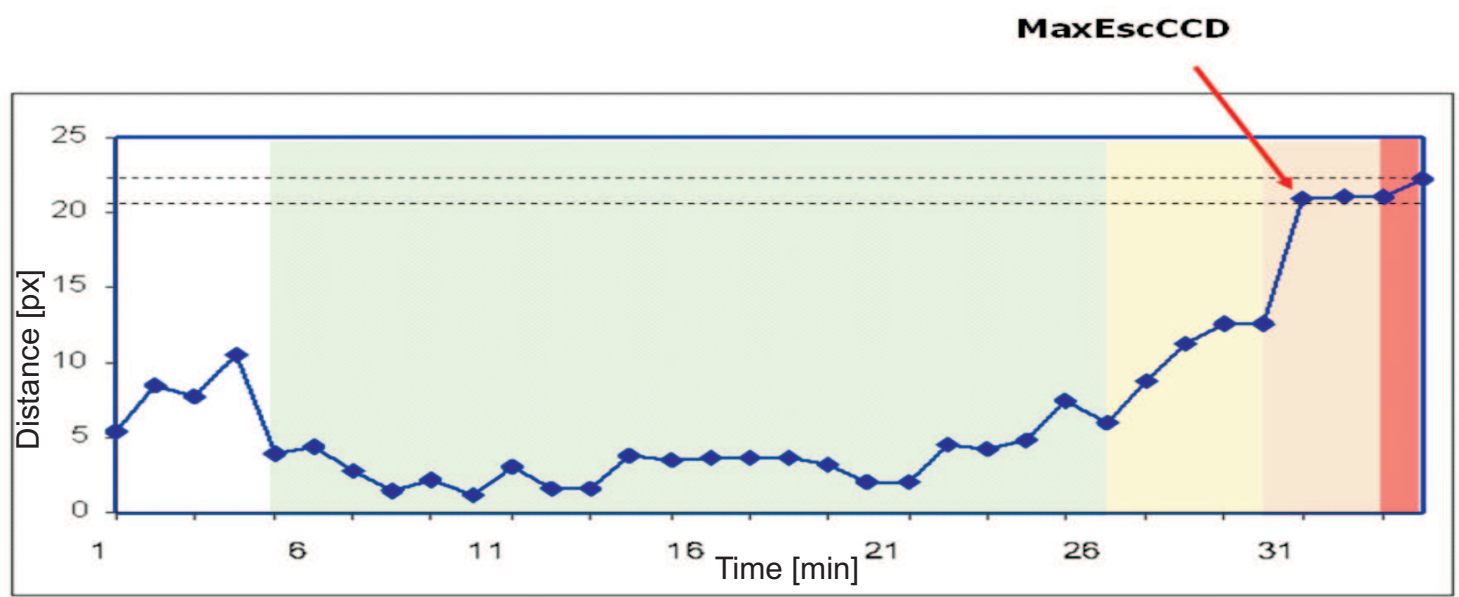

Fig. 4. Different taping phases during operation

However, it was not satisfying the fact that both concurrent systems (EMF and video analysis) must detect in seconds the same, that is to say the moment the tap hole must be closed, but because of both signal are separately processed, this does not provide a guarantee. In order to overlook this it has been designed, and begun to train a system based on fuzzy logic with sentences " if a and/or b.........then ....", as it can be found in the adjoining figure that functions in the following way.

\section{EMF Probes}

A system with the objective of determining the optimum moment to stop tapping is being developed in a European steel Industry and based on the analysis of electromotive force (EMF) signals (4). The electric scheme of a EMF probe is shown in the Fig. 5.

In Fig. 6 is shown the position of the probes in the Blast Furnace (5). Probes are welded to the shell in pairs at two levels, one used as a common voltage reference.

The EMF signal is analyzed continuously. (Fig. 7) and before, the signals are filtered through a program, smoothing to obtain a curve with fewer peaks and more homogeneous. After treatment gives a curve like that shown in the Figure 8.

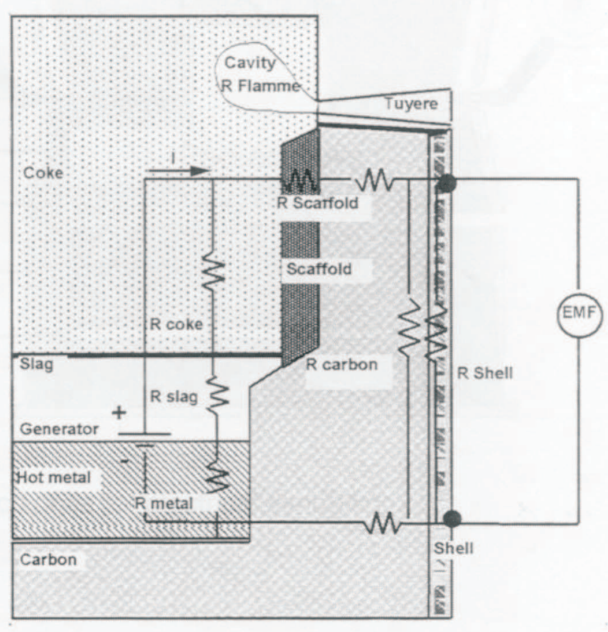

Fig. 5. EMF Probe 


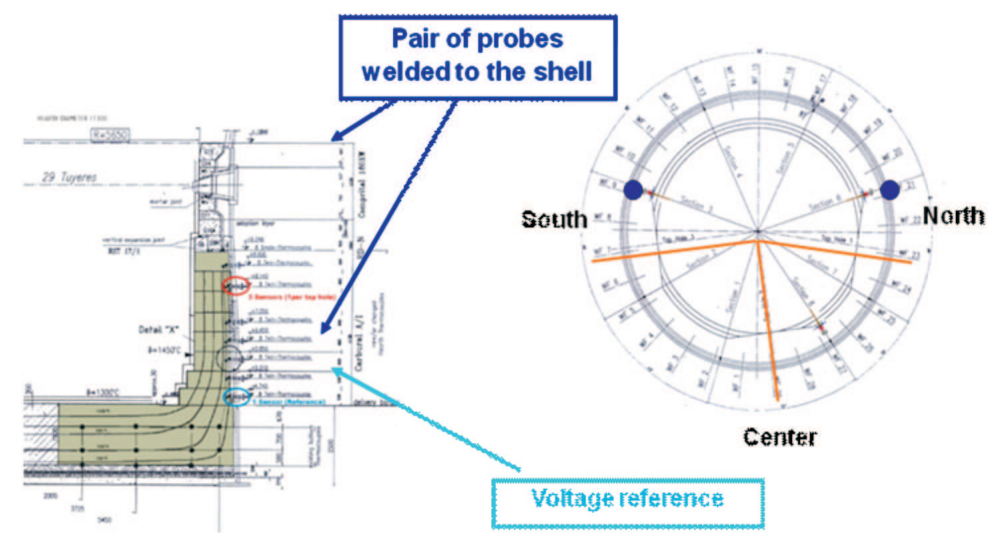

Fig. 6. EMF Probes situation at Blast Furnace \#B

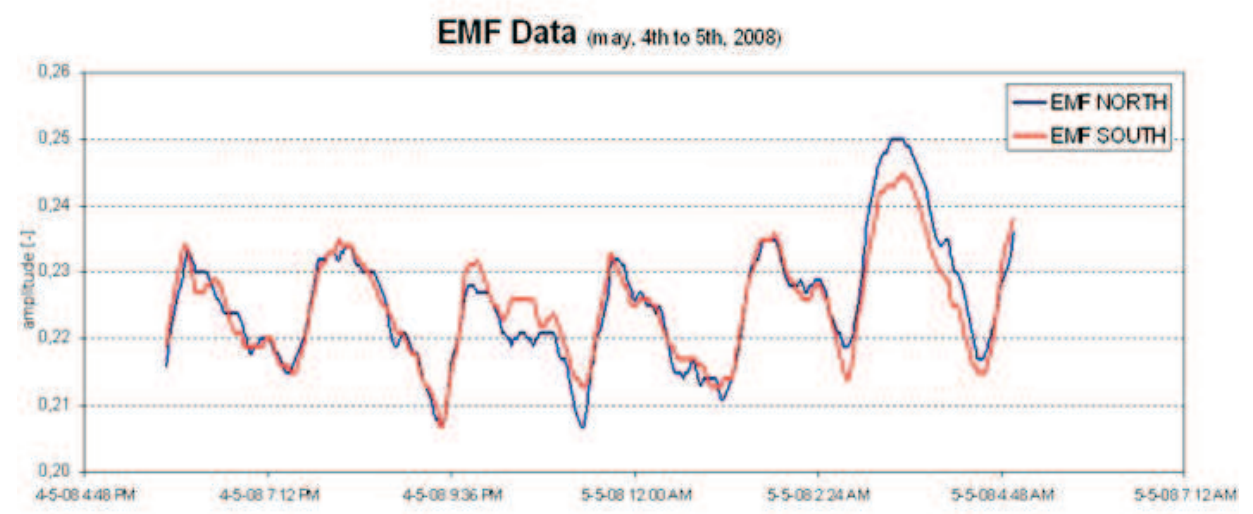

Fig. 7. Data from north \& south EMF

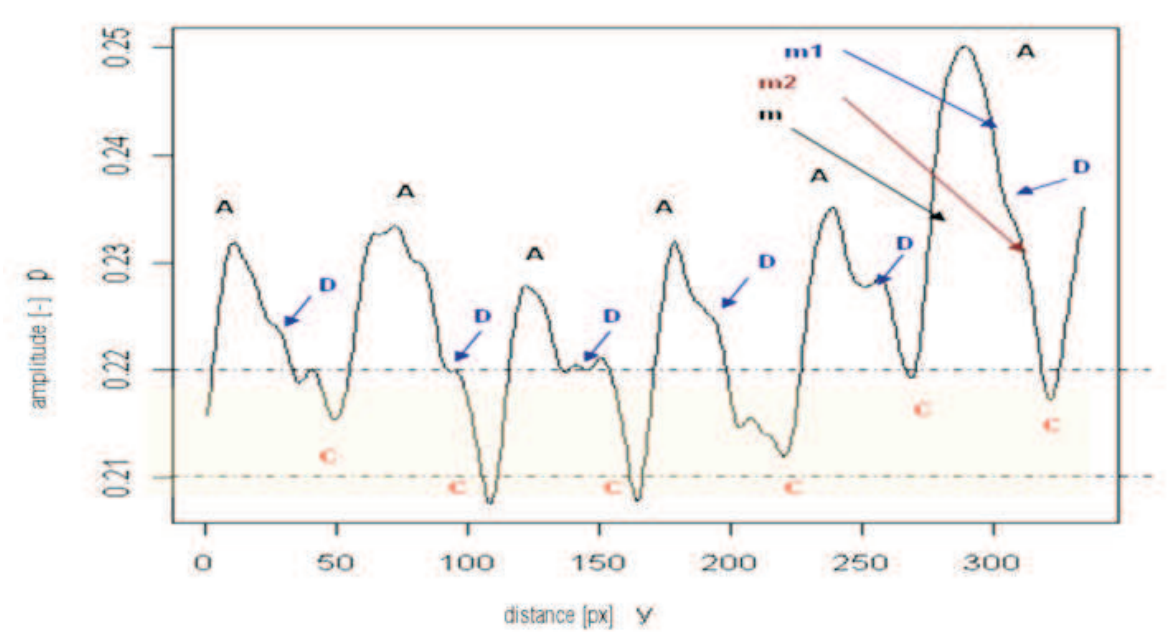

Fig. 8. Singular points of the taphole temperature EMF data.

As it can be seen in the Figure 8, there are some singular points, used in the fuzzy logic system.

1. Points ' $A$ ' are systematically detected (relative maximums, and associated inflection points).

2. Once a point ' $\mathrm{A}$ ' is detected and the descending section has begun, the F.L. system the start signal for slope " $m 1$ " is handed over.
3. In the descending sections (sections "AC") the inflection points ' $\mathrm{D}$ ' are detected in those that slope "m2" become more abrupt than for "m1".

Two EMF signal consignation points have been placed for the fuzzy logic system (6) Al: Those corresponding to amplitude 0,22 y 0,21 . 
The F.L. system (Figure 9) provides three exit points:
- Green light

- Amber light

- Red light (in two red color grades)

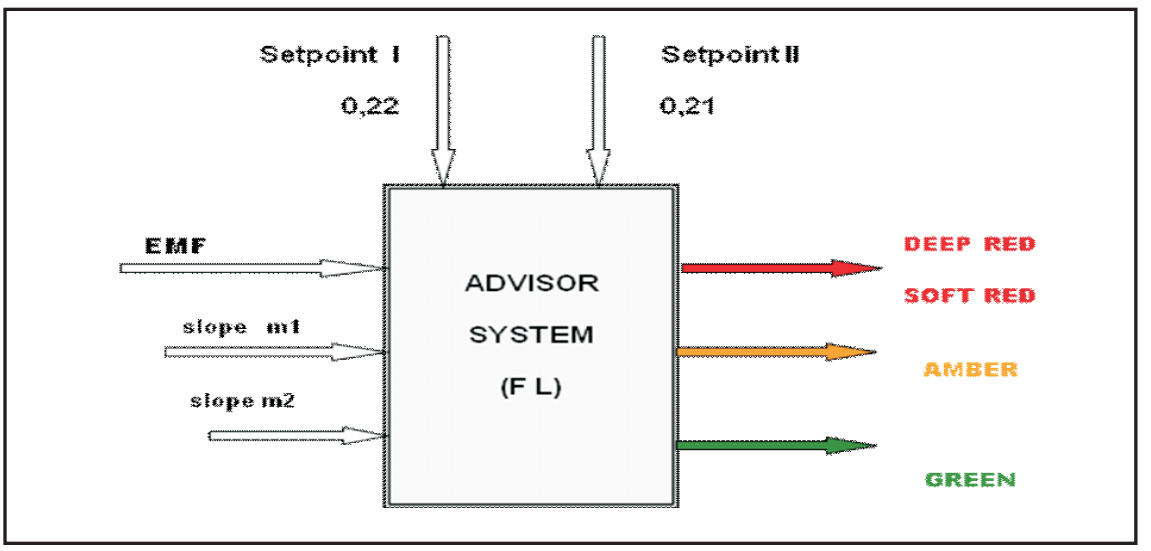

Fig. 9. Final "traffic lights" of the fuzzy logic system

In order to know how all the system works (7), it is determined for the different steps:

A. The value of the EMF signal is increasing, the Taphole is closed, No light signal

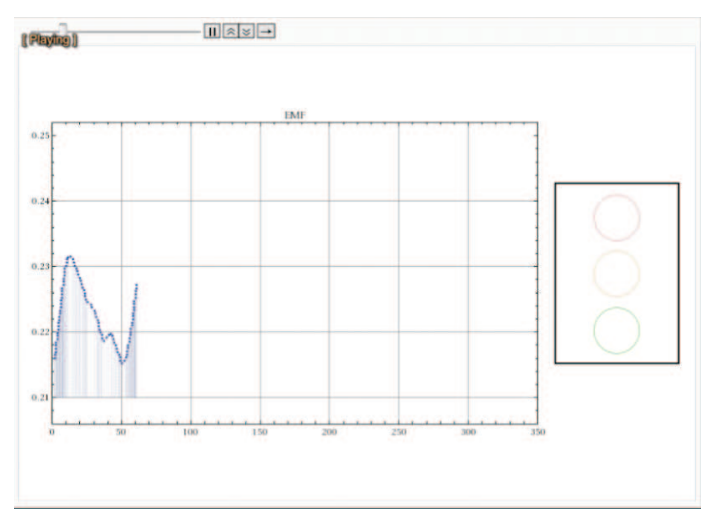

B. The curve reach a maximum (point A of the fig. 4.6) the taphole is open, the GREEN light turns on,

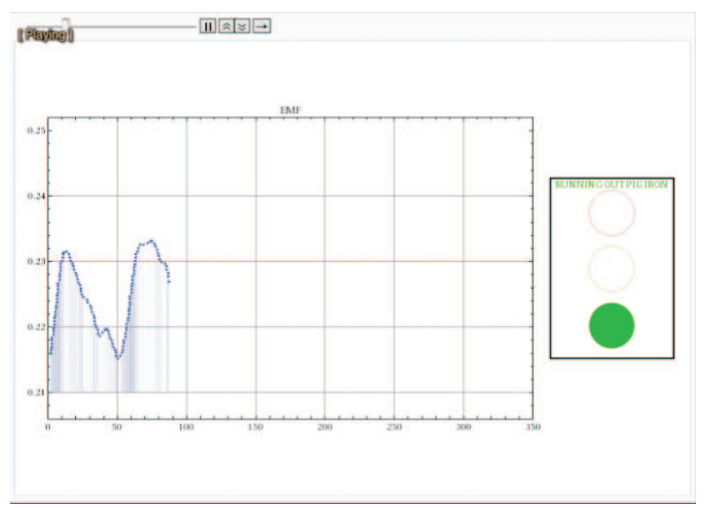

C. A change of the slope of the curve. The AMBER light turns on. The plant operator must control the taphole if there's any slag obstruction

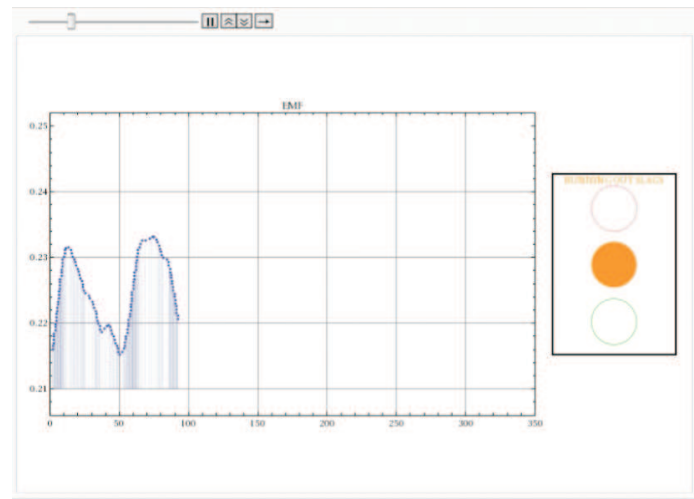

D. The value of the EMF probe past the first control setpoint, in this case 0,22 , the RED light turns on. The plant operator must be prepared to close the taphole

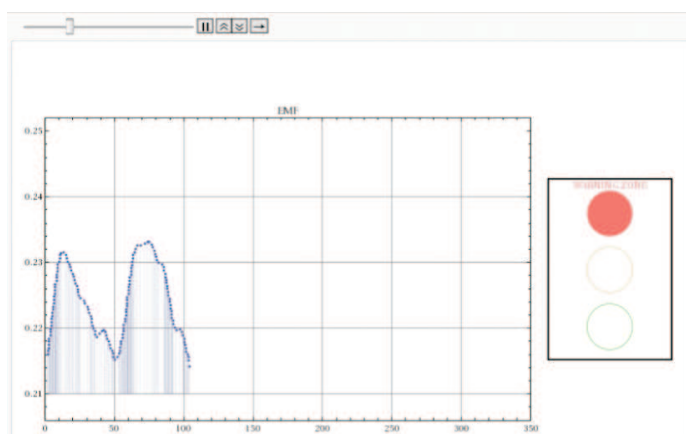


E. The value of the EMF probe has past the final control setpoint, $(0,21)$ the RED light turns on with more intensity, a sound can be used too, the plant operator must close the taphole

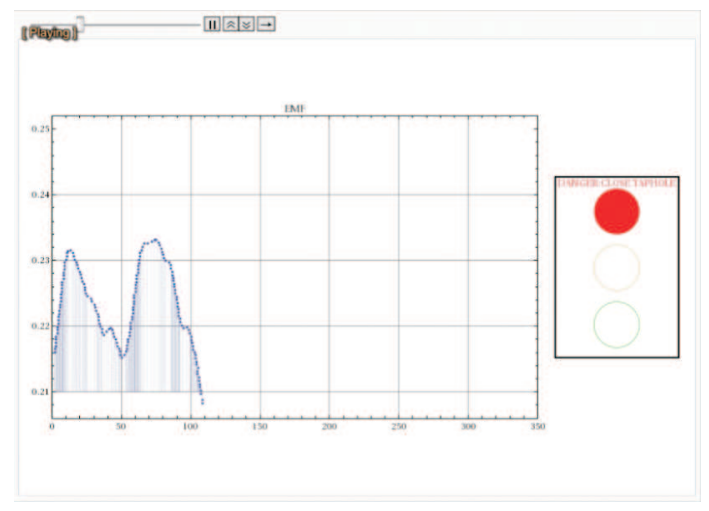

F. The value of the two setpoints are variables, can be decided daily using the information obtained from the process (8) in the previous days, using these, like inputs of the program.

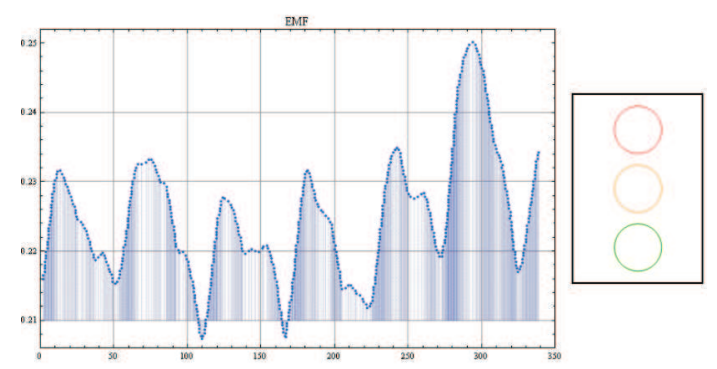

\section{Conclusions}

With the merging of two data sets, temperature from EMF probes and camera images, it has been provided a simple tool to help the operator to choose the best time for the different operations.
The change of slope in the descending part of the curve of the EMF data can indicate an obstruction of the taphole, this value change is due to the change of the hot metal / slag relation in the proximity of the taphole.

It's possible to obtain a relationship between the EMF probes values and the opening and closing of the taphole. CENIM has developed a mathematical program that can control the EMF values in order to help the plant operator in the decision of open and close the taphole.

\section{REFERENCES}

[1] Y.K. S u h, Y.J. L e e, C.Y. B a i k, A Study on the Flow of Molten Iron in the Hearth of Blast Furnace, Ironmaking Conference Proceedings, 35-38 (1996).

[2] W. Kow a $1 \mathrm{~s} \mathrm{k} \mathrm{i,} \mathrm{H.J.} \mathrm{B} \mathrm{a} \mathrm{c} \mathrm{h} \mathrm{h} \mathrm{of} \mathrm{e} \mathrm{n,} \mathrm{H.P.} \mathrm{R} \mathrm{u} \mathrm{th} \mathrm{e} \mathrm{r,}$ S. R ö d i, K. M a r x, Investigation on Tapping Strategies at the Blast Furnace with Special Regard to the State of the Hearth, Ironmaking Conference Proceedings, 595-606 (1998).

[3] O. M i e l e n z, R. K ó c hne r, M. P e t e r s, K.-P. $\mathrm{R}$ i i t h e r, P. S c h m o l e, Continuous measurement of hot metal mass flow rates in blast furnace plants. Stahl und Eisen 123, 12, 93-100 (2003).

[4] L.F. Verdeja, R. Go nzále z, A. O r dóñ e z, Using FEM to Determine Temperature Distribution in a Blast Furnace Crucible. JOM 52, 2, $74-77$ (2000).

[5] S.J. Ch ew, P. Zulli, A.B. Y u, Modelling of Liquid Flow in the Blast Furnace. Application in a Comprehensive Blast Furnace Model, ISIJ International 41, 1122-1130 (2001).

[6] R.D. Martín, F. Obesso, J. Mochón, R. B a r e a, J. Ji mé n e z, Hot metal temperature prediction in blast furnace using advanced model based on fuzzy logic tools. Ironmaking \& Steelmaking 34, 3, 241-247 May 2007.

[7] K. N i s ho k a, T. M a e d a, M. S h i r n i z u, Effect of Various In-furnace Conditions on blast furnace hearth drainage. ISIJ International 45, 10, 1496-1505 (2005).

[8] Y.K. S u h, Y.J. Le e, C.Y. B a i k, A Study on the Flow of Molten Iron in the Hearth of Blast Furnace, Ironmaking Conference Proceedings, 35-38 (1996). 